Supporting Police Community Support Officers to become effective School Link Officers: Key stakeholder perceptions of a pilot professional development programme

Dr Lorraine Thomas and Dr Dave Trotman, School of Education, Newman University, Genners Lane, Birmingham, B32 3NT, UK

Tel.: 0121476 1181, Email: 1.thomas@newman.ac.uk and d.trotman@newman.ac.uk 


\section{Acknowledgements}

The authors would like to thank the Police Community Support Officers, school-based mentors and the West Midlands Police (WMP) coordinating officer who participated in this research. The WMP coordinating officer was awarded the prestigious British Association of Women in Policing's Officer of the Year for her part in the programme. 


\title{
Supporting Police Community Support Officers to become effective School Link Officers: Key stakeholder perceptions of a pilot professional development programme
}

\begin{abstract}
This article presents the findings of a pilot professional development programme designed to support Police Community Support Officers (PCSOs) to become effective School Link Officers (SLOs) within urban secondary schools in the English West Midlands. Findings are presented via perceptions of key stakeholders: SLOs themselves; school-based mentors supporting the work of SLOs; and the West Midlands Police officer co-ordinating aspects of the project. The agreed professional development model comprised a two-day induction programme; school-based mentoring and coaching; and SLOs' reflections via a small-scale action research project.
\end{abstract}

Findings reveal the complexities of community policing in contemporary urban secondary school contexts and the challenges of enhancing the professional status of the SLO. Although PCSOs have been working as SLOs for several years, preparation for this role has been inadequate and the issue has generally been overlooked in literature. The pivotal role of effective school-based mentorship, opportunities for reflection and gaining national professional recognition via the action research project emerge as particularly positive features of the professional development model. With the ultimate aim of safeguarding young people, recommendations are also made to further develop the model to enhance SLOs' professional learning and effectiveness and maximise inter-professional working.

Key Words: Induction; Professional development; Mentoring and Coaching; School Link Officers; Teaching and Learning Academy 


\section{Introduction}

Prompted by West Midlands Police (WMP) concerns regarding the inadequate preparation of Police Community Support Officers (PCSOs) working as School Link Officers (SLOs) in secondary schools in the English West Midlands, WMP commissioned the School of Education at Newman University to design a pilot professional development programme for SLOs. Initially, a national accredited training programme was available to police officers working as SLOs in England as part of the 'Safer Schools Partnerships' initiative, but this has now ceased. Consequently, and as Lamont et al (2011, p. 14) explain, 'in the absence of such formal training, a number of different training practices have developed to equip police in schools with the knowledge and understanding necessary for this type of role.' As a result, training has become fragmented or non-existent in England, with officers often being left to devise their own strategies. These challenges then appear to have been exacerbated when PCSOs largely took over the SLO role from police officers.

Three key concerns and needs, which emerged from an internal questionnaire administered by WMP, were conveyed to Newman University: to improve the confidence and skills of SLOs to engage effectively with young people in secondary schools; to improve the partnership between PCSOs and school communities; and to raise the professional confidence and status of the SLO role. From discussions with WMP regarding their concerns for the preparedness of these 'para-professionals' (people to whom a particular aspect of a professional task is delegated but who are not licensed to practise as fully qualified professionals), a researcher from the University designed a professional development model to be piloted in two local policing units. When designing the professional development model for SLOs the researcher considered a wide range of effective continuing professional development (CPD) principles i.e. the facilitation of criticality and analysis (Eraut 1994); the importance of an in-depth, sustained programme (Kennedy 2005); the benefits of mentoring and coaching (Rhodes et al 2004, Forde and O'Brien 2011); the efficacy of professional learning linked to school contexts (Walker and Dimmock 2006); and the importance of regularly reflecting on and linking the teaching experience to the intended objectives in a structured way to inform and improve practice (Bringle and Hatcher 1999). Furthermore, the researcher considered the need for appropriate professional learning for PCSOs who undertake a para-professional role to support them in engaging with teachers about learning strategies; to facilitate the SLOs' acceptance into the professional environment of schools; and to allow them to "grow as professional educators" (Lyle and Hendley 2007, p. 205). The 
researcher also considered the experiences of the PCSOs to-date, who had no or few formal qualifications and what this might mean regarding self-esteem and self-confidence.

As a consequence, the agreed three-stage professional development model comprised an initial two-day induction programme for SLOs; a sustained and on-going programme of support for SLOs via school-based mentoring and coaching; and critical reflection via SLOs completing an individual action research project afforded by the Teaching and Learning Academy (TLA) CPD framework. The two-day induction programme aimed to introduce SLOs to key aspects of their role and working with young people in secondary schools. This was followed by a programme of support via school-based mentoring and coaching, with each SLO having a designated mentor. The pilot culminated in each SLO submitting an action research project regarding a crime prevention input for the award of national professional recognition via the TLA. The latter two activities also started to move the model beyond professional development and delivering input to greater professional learning, "in which individuals create professional knowledge through interaction with ... information in a way that challenges previous assumptions and creates new meanings (Timperley 2011, p. 5), supporting SLOs to advance their own learning and pupils' learning. Professional learning also epitomises "the key characteristics of reflective practice, critical evaluation and continuing learning" (O'Brien and Jones 2014, p. 684). The only aspects of the model proposed by the University which were not approved by WMP, due to police budgetary constraints, were the funding of a training event for mentors of SLOs and the funding of mentors to undertake TLA projects themselves alongside the SLOs they were mentoring.

\section{Context}

The role of the PCSO in England, introduced in 2002, was to be a defining feature of the former 'New Labour' government policy on neighbourhood policing (Quinton and Morris 2008). Echoing community policing practices initially developed in the Netherlands in the 1980s (Terpstra 2010) and more recently trialled in Canada (Dumaine 2005), as uniformed civilian members of police support staff PCSOs in England are non-warranted but have some police powers. PCSO duties are restricted to dealing with minor offences; early intervention to discourage criminal behaviour; crime prevention advice; conducting house-to-house enquires; and supporting front-line policing. As part of these duties PCSOs can be assigned the role of SLO where they are brought into direct contact with children, young people, teachers and the wider school community. Despite criticisms that community policing often 
lacks credibility and coherence (Johnston 2005) and despite concerns about the role, role definition and lack of training, the important role played by PCSOs as pivotal intermediaries between community and policing is widely recognised (Cosgrove and Ramshaw 2015, Foster and Jones 2010, Quinton and Morris 2008, Frondigoun et al 2012). In turn, an important corollary of this is recognition of the significant positive contribution of the SLO to school communities (Black et al 2010, Lamont et al 2011, Stead et al 2011, Clayman and Skinns 2012, Frondigoun et al 2013).

As Longstaff et al (2015) note, the police often struggle to work and communicate effectively with other agencies in the context of neighbourhood policing. Although keeping children safe and improving information sharing between agencies were key aims of New Labour's Every Child Matters policy (DfES 2004) leading to the amendment of The Children Act (2004), the role of the police alongside other services does not appear to have been fully considered. More recently there have been reports of improvements between Campus Officers in Scotland (the equivalent of SLOs in England) and educational staff, with information sharing being "viewed as an integral part of the campus officer role" (Black et al 2010, p. 2). SLOs could, therefore, potentially play a key role in working effectively with schools regarding safeguarding and information sharing. A positive example of professional development can be found in Wales, where some police officers working as Schools Liaison Police Officers have submitted portfolios as part of academic higher education studies, whilst working alongside teachers in schools to support their transition in becoming professional educators (Lyle and Hendley 2007).

Increasing acts of terrorism and extremism in the English West Midlands (where this research was undertaken) and across England and Europe mean that policing and community policing are now highly sensitive and topical issues, which impact on the lives of young people. We argue that SLOs can potentially play a key role as intermediaries within school communities, supporting the aims of and also offering an alternative/ additional strategy to the Prevent agenda (DfE 2015). Prevent is the British government's anti-radicalisation strategy, aiming to protect children and young people from being drawn into terrorism. Several issues have been raised regarding the Prevent agenda, however, not least of all concerns that it encourages a culture of surveillance (UCU 2015).

At the time of this pilot project PCSOs comprised $6.6 \%$ of the police force in England and Wales (Home Office 2013), but diminished resourcing has meant that many territorial police 
forces have recently announced plans to reduce the number of PCSOs in order to save costs leaving the future of PCSO roles uncertain. Notwithstanding the reprieve in the Autumn Statement from the wide-scale cuts planned to police budgets (HM Treasury 2015), United Kingdom (UK) police budgets are still limited and WMP has confirmed proposals to reduce its number of PCSOs following a wholesale review of local policing and as part of a wider plan to make savings (Gibbons 2015). Furthermore, PCSOs in the West Midlands were told of plans to significantly reduce their numbers by 2020 at a higher rate than police officers, triggering heated exchanges between PCSOs and senior WMP officers (McCarthy 2015). Concerns were also expressed by Unison and Unite - two of the largest trade unions in the UK - regarding public safety and concerns for their members who are already struggling with high staff shortages, additional workload and constant pressures from the government to reduce crime statistics (Gibbons 2015). Consequently, WMP initial plans to roll out this pilot programme more widely across the region have now been deferred due to uncertainties regarding the future of the PCSO in the region. Further to findings from Stead et al (2011, p. 13) that this type of "work in schools should continue to be prioritised, valued and funded", we argue that cuts in this area of policing remain an important oversight in the policing approach by policymakers, due to the potentially pivotal and proactive role PCSOs can play within communities.

\section{Methodology and participants}

This research adopted a mixed-methods research design (Johnson and Onwuegbuzie 2004) within a case study and used semi-structured questionnaires, focus groups and individual interviews to explore key stakeholders' perceptions of the pilot programme. Respondents comprised seventeen key stakeholders: eleven participating SLOs from two local policing units; five of their school-based mentors, who were experienced secondary school teachers and experienced in mentoring and coaching student-teachers and newly-qualified teachers; and the police coordinator, who had significant experience in community policing.

The research was subject to approval by the University's ethics committee detailing matters of informed consent, the right to withdraw, academic integrity and the security of data. Anonymity of responses was assured. Focus group and individual interviews were conducted in person by a contract researcher. Interviews were recorded and took approximately forty minutes. Interviews were then transcribed. 
Data were collected from SLOs at the start of the pilot programme via questionnaires and at the end of the pilot via focus group interviews. The SLO induction took place over two consecutive days in November 2014 and at the end of the second day all the SLOs completed questionnaires (securing a response rate of 100\%) to evaluate the induction programme.

SLOs completed TLA action research projects in March 2015. Eight of the eleven SLOs were then interviewed as two focus groups in April 2015 regarding their perceptions of the programme.

School-based mentors began mentoring and coaching SLOs in December 2014 and supported SLOs for the remainder of the pilot project until the end of March 2015. Data were collected from five of the participating school-based mentors through individual semi-structured interviews over April-May 2015.

The police coordinator was in regular contact with the SLOs, their school-based mentors and the University to discuss progress throughout the project. Data were then collected from the police coordinator within an individual semi-structured interview in April 2015.

\section{The three-stage professional development model}

\section{(i) Induction}

While police training normally lies within the province of its Learning and Development Department (LDD), diminished resourcing and police cuts, combined with the prioritization of training schedules for new police officers resulted in the LDD being unable to support or host the PCSO induction programme. Consequently, the programme was hosted at the University and mostly designed and delivered by the coordinating police officer, with additional input from other key stakeholders, including an experienced and deemed effective SLO; young people (boys and girls) and a senior leader from a secondary school; and University staff. In response to the outcomes of the WMP internal questionnaire regarding SLO needs, the induction programme was delivered around five core themes: PCSO powers and policy; aims and expectations of the SLO role; approaches to police engagement with young people and schools; strategies for effective learning and teaching in schools; and processes to undertake a small-scale action research project to aid reflection, leading to national professional recognition. Perspectives regarding the induction programme are provided below in quotation form and in turn from the SLOs via the semi-structured 
questionnaires completed at the end of the two-day induction and via the focus groups in which they participated at the end of the pilot; mentors via individual semi-structured interviews at the end of the pilot; and the police coordinator via an individual semi-structured interview at the end of the pilot.

Despite attempts to tailor the induction programme to SLOs' needs, there was a differing response from SLOs via the questionnaires, completed at the end of the two-day induction programme, and the focus groups, in which they had participated at the end of the pilot. On the one hand, most SLOs made positive comments within the questionnaires at the end of the two-day induction event about what they had learnt and how the induction had motivated them:

\footnotetext{
"From the talks with young people and other organisations I want to provide a service that young people will be proud of and build trust and confidence with young people."

"Certainly taught me more about researching for myself because, to be fair, I think for the most part, we didn't."

"What I found useful and appreciated was that you need to put that same message across but in different formats because children learn in different ways ... I wasn't aware of that."
}

On the other hand, around half of the SLOs criticised the induction programme during the focus group interviews at the end of the pilot regarding the level and language of sessions; and issues for which they considered the induction had not given them 'answers':

"It was ... over the top of my head."

"There was a lot of ... jargon used which ... I didn’t really understand.”

"I came out a little bit confused at the end of it."

"How do we deal with disruptive pupils who don't want to listen or learn?"

Interestingly, there appears to have been a shift in attitudes, with a positive response to the induction programme at the time, but a more critical response several months later.

Confusion and criticisms of professional development tend to emerge where the perception of the participants is that 'answers' to encountered problems have not been at the forefront of their training (Jackson 2009, Bauer \& Brazier 2012). In this case, some SLOs considered the induction had not given them the 'answers' they needed concerning difficult issues, such as behaviour management. These seemingly contradictory perceptions are, however, not uncommon. In the field of initial teacher education (ITE) and CPD for teachers, it is not unusual for participants to regard their training as either overly-theoretical or of limited practical value unless this is effectively mediated in school, in order to address the gap 
between theory and practice. This suggests, therefore, that some SLOs did not see the benefits of linking theory with practice and/ or perhaps these links were not made explicit. It is the responsibility of educators, however, to interpret and apply theory in a manner conducive to building knowledge, that is both a solid foundation for future learning and which can be applied in practice (Bruner 1986). This is an important area, as the links between theory and practice are known to be problematic, yet practice can be greatly advanced if this issue is addressed effectively (Korthagen and Kessels 1999). Also, integrating the role of the school in participants' learning can improve the linkage between theory and practice (Simkins 2009). Furthermore, Browne-Ferrigno (2003) has shown that some teachers feel confusion where there is a 'duality of identity', in undertaking additional learning alongside professional practice, which aligns with the confusion felt by SLOs who considered they were being asked to undertake a teaching, rather than policing role, when working with young people in schools. Added to this, as White and Heslop (2012) point out, the involvement of the university sector in police education and training is very much in its infancy in comparison with that of teaching. Highlighting the quite different philosophical orientations each has to training and development, teaching is typically associated with liberal education and critical thinking, whereas policing is more commonly associated with matters of state control and the constraints of citizenship, which typically frame learning in terms of task performance and vocational competence (White and Heslop 2012). In this context it may go some way to explaining the criticisms from some SLOs of their induction. Moreover, the ambitions of the programme to promote effective practice by SLOs in schools also lie at the nexus of multi-professional practice, which, in this instance, demands that the police, schools and University work together effectively to improve young people's understanding of crime prevention and staying safe.

Only one mentor discussed the induction programme and this was to comment on the lack of engagement with mentors at the initial induction stage of the project:

\footnotetext{
“... maybe when the PCSOs get invited to Newman University it might be a good idea for the link teacher from the school to be invited as well, ... so ... we can compare and contrast the provision from the University ... so that thinking can be joined up a little."
}

The mentor suggests that it would have been beneficial for school-based mentors to attend the SLO induction programme, so that they could experience the SLO induction for themselves too. The university researcher had advised WMP to fund a separate training event for schoolbased mentors of SLOs, in the same way as universities provide separate training events for 
school-based mentors of student-teachers within ITE programmes, but this had not been possible due to budgetary constraints. School-based mentors are qualified and experienced teachers, however, who would have needed a different type of training event focusing on the mentoring and coaching role, rather than attending the event designed for the SLOs' needs. Nevertheless, the mentor makes an important point around the efficacy of learning linked to school contexts (Walker and Dimmock 2006) and if additional funding had been available for a mentor training event it would have been beneficial to discuss the SLO induction programme with mentors, so they had a greater understanding of the SLOs' needs, which would further enhance the coherence of the professional development programme and thereby support the exchange of professional expertise.

In contrast with some SLO criticisms of induction and despite the different philosophical orientations and different professional values and practices between the police and university sector, the police coordinator appreciated the University's approach to encourage SLOs to use facilitation and discussion, rather than didactic instruction with young people in schools. The police coordinator commented that the University's contribution to the induction programme:

“... gave them a number of tools and different ways that they can actually engage with young people ... rather than just standing at the front and doing the input, which is traditionally what we do as police officers - just go in and say "Don't take drugs" or "Don't do this" - she gave them the tools to actually getting a bit of facilitating, ... conversation with them."

The University contribution encouraged SLOs to work with young people within an andragogical approach (Knowles 1990), based on the social constructivist approach of teachers as facilitators of learning (Vygotsky 1962), in order to move SLOs beyond didactic instruction into facilitating reflection and discussion. This aligns with findings from Stead et al $(2011$, p. 7) that "interventions which use skill based interactive teaching styles are more effective in relation to young people's behaviour" in these contexts. Furthermore, this aligns with guidance from the National Union of Teachers that discussion within schools would make a better contribution than the Prevent agenda to counter any behaviour that could be a problem (Blower 2016).

The police coordinator also expressed disappointment that the police's own LDD trainers had been unable to deliver aspects of the induction programme: 
"That's probably where we've fallen a bit short. ... I would have liked support ... it was quite ironic really ... delivering training to officers because they hadn't had any training and we felt that was important and yet I was delivering it and I hadn't any training how to deliver it!"

The lack of support from the LDD meant, therefore, that the majority of the induction programme had to be delivered by the police coordinator herself and she acknowledged her lack of experience in delivering training and the irony of this position. Studies in other settings, such as health care and medicine, have consistently underscored the challenges that surround inter-professional education (Robinson and Cottrell 2005, Reeves et al 2008). Much of the research points to issues around reconciling different professional values and practices; conditions of service; and the need to invest in joint training and professional development. It is suggested, therefore, that investing in collaborative delivery by the LDD, University and schools would have further improved induction and ultimately benefitted SLOs and young people in schools.

\section{(ii) School-based mentoring and coaching}

As previously discussed, integrating the role of the school in participants' learning can improve links between theory and practice (Simkins 2009). Consequently, the University researcher proposed that school-based mentors were assigned to support SLOs in several ways: planning and preparing sessions for young people; engaging SLOs in reflective dialogue following sessions, to advance their learning and practice; and in undertaking their individual action research project. Perspectives of the school-based mentoring and coaching are provided below, which include comments from the SLOs via the focus groups in which they participated; mentors via individual semi-structured interviews; and the police coordinator via an individual semi-structured interview.

SLO comments regarding mentoring and coaching appear to indicate that the role of the mentor was largely a significant contributor to the success of the programme:

\footnotetext{
"She was brilliant... but to be fair, my school's brilliant. I've got a really good close working relationship with ... the school."

“... very pro-police and also he's an ex-special constable himself, so he knows the background and he knows how it works. ... he was very sympathetic and every time I sent him any emails and said "This is what I'm doing. Am I on the right track?" ... he would get back to me with very constructive criticism."
} 
"When we delivered our inputs to the pupils, by the time we came round to the third and fourth one it was so much easier and I was starting to feel a bit more confident about dealing with the pupils. ... now, going in, it's ... not quite as daunting."

"I felt like I'd been a niggle to her a lot of the time 'cause she's got more important work in her school to do, so I think the mentoring is an absolutely fantastic idea but ... you've got to be careful on who you choose to mentor you."

In most examples the mentors' sensitivity and commitment were apparent, revealing the positive interpersonal relationships established between SLOs and their mentors. The second comment also demonstrates the importance of understanding the context, since this mentor's former role as a special constable played a significant part in his ability to mediate the discourses of policing and teaching that other mentors may have found more challenging. Nonetheless, effective mentoring of SLOs mirrors much of the reported best practice in the context of ITE (Hobson 2002) with mentoring underpinned by principles of reflective practice (Schön 1983), dialogic teaching (Wells 2004) and constructivist learning approaches (Dewey 1904, Piaget 1972, Bruner 1996, Perkins 1999), leading to SLOs' growing professional confidence due to reflective discussions and the supportive and constructive feedback provided. Also, Lyle and Hendley (2007, p. 205) assert that para-professionals who start to engage in discussions with teachers about learning strategies "will become more accepted by them and be treated more and more as fellow professionals". As the final comment shows, however, it is essential to ensure appropriate school-based mentors are assigned who have the necessary time to commit to the role. If chosen appropriately, schoolbased mentors can be key to unlocking difficulties in linking the theory and practice of learning and teaching, in order to make a real contribution to improving SLO practice and safeguarding young people in schools.

Although WMP had been unable to fund mentor training, as experienced mentors of studentteachers and newly-qualified teachers, most school-based mentors of SLOs were wellpositioned to assimilate this role quickly, due to the remit provided of mentoring and coaching SLOs in a similar way as if working with student-teachers. All mentors had agreed to undertake the role to support SLOs and the responses of those interviewed demonstrate that they had mostly understood what had been expected of them and also exemplify some of the benefits of school-based mentoring and coaching to their pupils and the SLOs. Some illustrative comments from mentors regarding school-based mentoring and coaching can be found below: 
"We planned the safety day ... they [the SLOs] sent me their resources beforehand ... I looked through ... talked through their ideas and they ... carried on from there. ... I asked them how it went and we ... had an informal ... discussion about ... rather than talk at people, try and engage them actively. ... Everything takes time ... but I think the pay-off is ... beneficial."

“... there's a development in the building of ... confidence in being able to communicate to a group of students. ... her [SLO] self-confidence improved because we had walked the walk ... prior to the delivery of the actual activity ... but the activities that she used in the delivery as well, it was champion. ... I think as a result of the project and the fact that Newman University afforded them this opportunity in partnership with a number of different schools ..., in my opinion it's quids in.”

"I've had some feedback from the member of teaching staff that accompanied the PCSO ... and he said that the session was well-planned, well-delivered and the pupils learnt a good deal, so it was positive feedback. ... The PCSO ... discussed ... the Citizenship Days he'd contribute to ... we discussed the topic, ... he devised something, sent it to me via email, I made suggestions. ... He ... looked at the less effective parts, sent me a final version back, I okayed it and that's what he came in and delivered. So, there was a real discussion about ... how he could improve it, ... so that's really what I've really thrown myself into ... not just saying "yeah come in and deliver us a session on this, off you go." We've really tried to work with him to make sure ... what he delivers is a quality session ... and ultimately the pupils have benefitted."

The need for joint planning and discussions between teachers and officers raised within the comments were also recognised as being necessary for the effective delivery of sessions by Stead et al (2011). Clearly, constructive dialogue between SLOs and mentors facilitated exchanges of different professional expertise and, in turn, underscored further the opportunities for promoting a more authentic inter-professional exchange between SLOs and teachers. The above comments also highlight the pedagogic benefit to young people, which should support safeguarding, and a range of benefits for SLOs, such as improving their reflective practice, professional confidence, communication skills and their understanding of pedagogy.

The police coordinator perceived the school-based mentoring and coaching to be very effective and identified some key improvements being made as a result:

“... we did have issues where people were delivering inappropriate material to different age groups ... so this is a way of keeping a check from an organisational perspective, making sure that the school okays what is delivered before it's delivered."

“... issues which ... the PCSOs would never have tackled because it's just such a complex area they'd be concerned about getting complaints or not getting it across correctly ... but with dedicated support of a one-to-one mentor ... it's tackled by the school and the police so it's a real partnership and it's signed off by the school to say "we're happy for this to be delivered."'

Data collected within this research reveal that SLOs are working in more complex contexts than originally conceived. In contrast with those policing priorities traditionally encountered by PCSOs, the context for their work clearly presents relatively new forms of challenge, 
which has been addressed somewhat by mentoring and coaching support. The spectrum of issues noted by participants in the research typically encompassed child exploitation, cyber abuse/criminality, extremism, terrorism and female genital mutilation. Echoing this increasing complexity in community police work, Longstaff et al (2015, p. 27) note the need for longer-term solutions based on a 'detailed understanding of the multiple and persistent problems'. These problems, they conclude, involve high concentrations of poverty and illhealth; poor physical environment; a large number of low-income families; limited neighbourhood resources; an active drug market; and substantial barriers to offender resettlement (Longstaff et al 2015). It follows that these localised social complexities are also manifest in school contexts and particularly in secondary schools, where the transition of young people through school coincides with significant physical, mental and emotional change. One such longer-term solution can be found within a programme such as this one, comprising sustainable mentoring and coaching support for SLOs. The police coordinator also came to recognise the essential role being played by mentors, what was needed from them and the importance of mentors' willingness to actively support and participate in the project:

\footnotetext{
"The mentor is the absolute key role. ... we've just had what we call our Blueprint for 2020 produced and in neighbourhood policing it talks about sharing and using the talents of our partners in helping us to deliver a better service to our communities and this project fits perfectly with that because it's using the talents of our schools to assist us to give them a better service."

"we're trying to deliver a better service to the schools, so by investing in our officer they're [the mentors] ... hopefully going to gain so much from that relationship."

“... absolutely fantastic. From the beginning there's buy-in."

"One of the best examples of where it's working is that the officer was receiving very close one-to-one support from someone within the school."
}

These comments highlight the perceived reciprocal benefits of inter-professional and partnership working. They also demonstrate the needs of the police to gain mentors' full commitment and the need for mentors to understand the context of the SLO role.

\section{(iii) Action research via the Teaching and Learning Academy CPD Framework}

Considering the appropriateness of action research to introduce the SLOs to a circle of planning, action and evaluation (Lewin 1946, McNiff and Whitehead 2009), the University researcher proposed that the pilot programme culminated with SLOs undertaking "practical 
action research', which is akin to reflection-on-action (Schön 1983). Due to the PCSOs' low levels of confidence in the teaching aspect of the SLO role, school-based mentors were asked to support SLOs with their individual TLA action research projects. Originally launched as the Teacher Learning Academy in 2004 by the former General Teaching Council for England (GTCE) as its professional development strand, the TLA was deemed a highly successful CPD framework with a range of common positive impacts for school improvement (Lord et al 2009). After the GTCE was abolished, the TLA was subsequently bought by the Cathedrals Group of universities in November 2011 and relaunched as the Teaching and Learning Academy, with a modified structure to ensure that a wider audience beyond teachers, such as teaching assistants in schools and in this instance SLOs in the police, may take advantage of the framework and the opportunity to gain national professional recognition and also academic credits via the accreditation of prior experiential learning. The TLA is now a professional development strand of the Cathedrals Group of universities and Newman University is the regional TLA provider for the Midlands area. Perspectives of the TLA are provided below and drawn from SLOs via the focus group interviews; mentors via individual semi-structured interviews; and the police coordinator via an individual semistructured interview.

Some SLOs initially struggled with the concept of national professional recognition, questioning "What is the qualification?" which may again highlight the different philosophical orientations and priorities the university and police sectors have to training and development. Nevertheless, the culmination of the pilot programme was the submission by the SLOs of an individual action research project regarding a crime prevention input and all eleven SLOs completed their projects. For many of the SLOs interviewed the completion of the TLA project requirement was not a simple undertaking. The following comments typified many of the perceived challenges regarding undertaking written reflective commentary on aspects of their work, often for the first time:

\footnotetext{
"It actually gave me nightmares."

"I used to wake up in the night and write notes. It was on your mind twenty-four-seven."

"Well, I took mine [TLA project], she [the mentor] looked at it and said "I can't help you with that. ... I've never seen anything like that before.” ... You wouldn't think teachers would have problems. ... the paperwork wasn't easy at all."
}

Some of these comments are indicative of the considerable practical challenges and psychological anxieties that confront adults in both returning to learning and engaging with 
forms of CPD comprising reflective writing that are new or alien to their prior experience. As Boud (2001, p. 15) observes, this necessarily requires an environment where participants are not preoccupied with defending themselves from the scrutiny of others but enables 'the questioning of assumptions about oneself, one's group, or the conditions in which one operates', which is essential for critical reflection and understanding one's practice. Despite the attendant anxieties, all eleven TLA projects were successfully verified although the SLOs did not know this at the time the focus group interviews had taken place, as they had only just submitted their projects for verification. From the emails sent to the University by the SLOs expressing their delight and relief upon receiving their TLA certificate, however, and reports from the police coordinator it was evident that the personal pride in achieving TLA national professional recognition had been significant to the SLOs. The final comment also shows that some mentors were unable to support SLOs in completing the TLA project, however. Although the University researcher had recommended the inclusion of TLA projects for school-based mentors within the proposed professional development model, WMP had been unable to fund this aspect, due to budgetary constraints. Consequently, some mentors were not familiar with the TLA requirements and were unable to support the SLOs adequately with their project. If school-based mentors had been completing TLA projects alongside the SLOs this would have enabled them to more effectively support the SLOs; alleviated some of the anxieties experienced by the SLOs; stimulated some collaborative professional learning, which could also facilitate greater understanding from both the school and police sectors regarding each other's practice; and may also have demonstrated further appreciation and acknowledgement of the work mentors were undertaking.

Some mentors had taken the time to familiarise themselves with the TLA requirements, however, and were aware of the benefits of TLA projects:

"It's [the TLA] ... is valuable 'cause it goes on to inform other PCSOs and other police officers and because it's quality that's being produced it then gets put onto their systems, so they can be used elsewhere."

This mentor clearly acknowledges the quality of the work being produced via the TLA projects and the importance of disseminating them. The University researcher had encouraged WMP to use verified TLA projects in the induction of future SLOs and to share projects via an online platform, facilitating peer support and enhancing the sustainability of the programme. Although WMP had been unable to fund mentors to undertake TLA projects, as teachers who themselves had had to gain the national professional recognition of qualified 
teacher status via meeting professional standards (see DfE 2012 for example) and as experienced teachers accustomed to the use of critical reflection to inform their planning to support pupil progress, most school-based mentors were well-positioned and able to support SLOs with the TLA project.

Finally, although the police coordinator had initially been reluctant to include the TLA project within the pilot programme, since many PCSOs do not have any formal qualifications, she saw the merits of the TLA and was reassured by the projects not being assessed at any specific academic level, but rather being verified relating to reflection of professional practice. Interestingly though, the TLA seems to have been an especially significant aspect of this programme because PCSOs who typically have no or few formal qualifications were able to gain national professional recognition from their projects. As such, national professional recognition through the partner university has provided an essential conduit to an evaluation of practice that accords more sympathetically to the tenets articulated in the discourses of neighbourhood policing and provided an effective entrée to a more systematic reflection on professional learning. Once SLOs started to engage with and complete the TLA projects, the police coordinator became convinced of the benefits of the TLA:

"That's [the TLA] been one of the best bits for me personally about the project. ... they [the SLOs] seem to have such a pride about it."

"I think that's where the training has really happened."

“... we've had a whole range of projects coming back and it's really gratifying for me to see ... stuff that I heard about on the training day ... they've actually used.”

“... showing ... the way in which the police want you [the SLOs] to design future crime prevention input. If the school comes to you and says we've had a problem with cyber bullying ... can you deliver an input? What you should be doing is exactly the process ... you've done for this. .. The Teaching and Learning Academy ... has given us the perfect ... purpose in what they're doing ... and also ... to meet up with someone in that school ... with a purpose."

“... it's [the TLA] very do-able because ... the teaching and learning ... they [the SLOs] do is what they're doing anyway - just in a more structured and supervised way. ... all that we're doing is asking them ... to actually reflect on that process ... I feel personally that the police should do more of this kind of self-reflection. We are a professional organisation and I think that should be part of our work anyway."

“... they're [the TLA certificates] are going to be presented by senior leaders to the PCSOs because I think we should celebrate what is a real achievement for them."

“... talking about more complex issues ... that's [the TLA] actually been a great success of the project. ... one of the PCSOs ... will ... be submitting a project on talking to young people about the dangers of extremism and terrorism and travelling to Syria etc." 
For the police coordinator the TLA was key to the programme and met the aims of improving crime prevention inputs, providing PCSOs with significant learning via effective CPD and the credentials of national professional recognition; affording an improvement in the SLOs' reflective practice; providing SLOs with a renewed purpose and a sense of pride in their achievements; and supporting them in engaging with complex issues, which would previously have been avoided. It was also pleasing to hear that the police coordinator had taken on board the positive ethos and celebration events associated with the TLA from its initial introduction by the GTCE, since the TLA is a CPD framework which embraces a celebration of achievements. The police coordinator also reported the enhanced professional status of SLOs as an ambition of the WMP Chief Superintendent and Chief Inspector overseeing the project and this was another reason for the police coordinator accepting the TLA action research project within the training model. For the police coordinator, enhancing the professional status of PCSOs was fundamentally about engendering personal and professional pride and involved officers making some initial gains in confidence-building and improvement regarding the delivery of input when presenting policing issues to young people. The adoption of TLA action research projects by SLOs culminating in national professional recognition was a direct attempt by the University to support aspects of SLOs' professional learning and practice and to enhance their professional status with regard to credentials.

\section{Conclusion}

Despite the challenges relating to the PCSO role, the findings from this research demonstrate that this CPD programme made significant steps forward to address the issues which initially emerged from the internal questionnaire administered by WMP i.e. to improve the confidence and skills of SLOs to engage effectively with young people in secondary schools; to improve the partnership between school communities and community policing; and to raise the professional confidence and status of the SLO role. Overall, the findings offer a positive account of a professional development initiative and the professional exchange of expertise between higher education, the police and schools. The accounts from participants reveal the value of each element of the pilot professional development programme and also aspects which could be developed, should this model be rolled out further across the police force. The findings show the quite different philosophical orientations higher education and the police have to professional development, which underscores the need for greater 
collaboration in the training of SLOs, to facilitate the exchange of different professional expertise and to promote a more authentic inter-professional exchange across the police, higher education and schools. Consequently, we propose that the current model is developed further to enhance SLOs' professional learning by fully integrating all three partners, with schools and the University working in greater partnership too. Recommended improvements are: collaborative planning and delivery of the induction programme by the police LDD, the University and the secondary schools; the allocation of appropriate school-based mentors with the necessary time and expertise to support SLOs; the funding of mentor training; funding for the mentors to undertake TLA projects themselves alongside the SLOs; and a need for the police, University and schools to collectively celebrate the SLOs' achievement of TLA national professional recognition.

The findings offer a positive account of a burgeoning partnership of strong mutual benefit established via the CPD programme between the police, higher education and schools, which has also been effective in further improving relationships between the police and young people and between the police and school communities, which in turn may support the safeguarding of young people. It has also been evident from the pilot CPD programme that effective police-University-school partnerships and interventions can be achieved with modest resourcing, but providing good impact. The project has also demonstrated to the police and schools other types of contribution higher education can make to society, such as designing and providing appropriate, high quality and sustainable professional learning; and offering professional credentials, in addition to the important core academic role of higher education and the concept of the ideal university as a community of thinkers, engaging in intellectual pursuits not for any external purpose, but as an end in itself (Newman 1959).

Much less encouraging though is the policy context within which neighbourhood policing now has to operate. Despite the positive developments achieved by this CPD project and PCSOs achieving more inclusive engagement in local communities, Cosgrove and Ramshaw (2015) note that PCSOs' efforts are mitigated by their structured position in the hierarchy and the organizational environment in which they work. Furthermore and despite the ambitions of WMP via this pilot to provide effective professional development for SLOs, at the time of writing serious doubt exists around the prospects of neighbourhood policing and the future of PCSOs as a consequence of on-going funding constraints (O’Neill 2015). As Foster and Jones $(2010,77)$ observe, there is a common perception that neighbourhood policing is "nice to do but not essential" and in particular CPD for PCSOs continues to be a marginal feature 
of police training, as funding settlements are prioritised amongst other competing divisions of policing. These findings, however, offer a further insight into the importance of a clear direction for PCSO-SLO professional development and for community policing. Underscoring Longstaff et al's (2015) assertion that the police sometimes struggle to work effectively with other agencies in the context of neighbourhood policing, combined with the significant differences noted by White and Heslop (2012) in education and training in policing and teaching, this research highlights the urgent need for an inter-professional approach to SLO professional development, but also provides a positive way forward and successful model as a major outcome of the findings. Also, if the PCSO role has no future then it is imperative that warranted police officers undertake the SLO role and are offered appropriate professional learning to ensure the pivotal role of community policing is secured. If policing strategy is to engage effectively with the contemporary socio-cultural complexities reported by the respondents in this research and address safeguarding in a more meaningful way, then a commitment by policymakers to invest in a coherent, in-depth and sustained CPD programme, such as the recommended model, would appear to be an essential prerequisite and could be an effective addition or alternative to the current Prevent agenda. 


\section{References}

Bauer, S. C. and Brazier, S. D., 2012 Using Research to Lead School Improvement: Turning Evidence into Action. California: Sage

Black, C., Homes, A., Diffley, M., Sewel, K. and Chamberlain, V., 2010 'Evaluation of campus police officers in Scottish schools', Scottish Government (Scotland) / Ipsos MORI Scotland [accessed 01/05/16] Available at http://dera.ioe.ac.uk/1225/1/0095816.pdf

Blower, C., 2016 National Union of Teachers (NUT) Annual Conference (28/03/16)

Boud, D., 2001 Using Journal Writing to Enhance Reflective Practice New Directions for Adult and Continuing Education. 90, 9-18

Bringle, R. and Hatcher, J., 1999 Reflection in service-learning: Making meaning of experience Educational Horizons, 179-185

Browne-Ferrigno, T., 2003 Becoming a Principal: Role Conception, Initial Socialization, Role-Identity Transformation, Purposeful Engagement Education Administration Quarterly, 39 (4), 468-503

Bruner, J., 1986 Actual minds, possible worlds. Cambridge, MA: Harvard University Press Bruner, J., 1996 The Culture of Education, Cambridge, MA: Harvard University Press Clayman, S. and Skinns, L., 2012 To snitch or not to snitch? An exploratory study of the factors influencing whether young people actively cooperate with the police Policing and Society, 22 (4), 460-480

Cosgrove, F. and Ramshaw, P., 2015 It is what you do as well as the way that you do it: the value and deployment of PCSOs in achieving public engagement Policing and Society, 25 (1), 77-96

Department for Education (DfE) 2012 Teachers' Standards London: Her Majesty's Stationery Office

Department for Education (DfE) 2015 The Prevent duty: Departmental advice for schools and childcare providers London: Her Majesty's Stationery Office

Department for Education and Skills (DfES) 2004 Every Child Matters: Change for Children in Schools, Nottingham: DfES

Dewey, J., 1904 The Relation of Theory to Practice in Education. In C. A. McMurry (Ed.), The Third Yearbook of the National Society for the Scientific Study of Education. Part I. Chicago: The University of Chicago Press

Dumaine, F., 2005 Future Directions in Community Policing: Evaluation of the Ottawa Police Service Community Police Centres The Canadian Review of Policing Research, 1 Eraut, M., 1994 Developing Professional Knowledge and Competence London: Falmer Press 
Forde, C. and O'Brien, J., 2011 Coaching and Mentoring Edinburgh: Dunedin.

Foster, J. and Jones, C., 2010 'Nice to do' and Essential: Improving Neighbourhood Policing in an English Police Force Policing, 4 (4), 395-402

Frondigoun, L., Smith, R. and MacLeod, I., 2013 "Exploring the Role of Campus Officers in Scotland", Article in the SIPR Annual Report - pgs 22-23.

http://www.sipr.ac.uk/downloads/SIPR_Annual_Report_12.pdf

Gibbons, B., 2015 "More than 500 police and community support officer roles axed at West Midlands Police" Birmingham Mail [online] (10/11/15) [accessed 26/12/15] Available at http://www.birminghammail.co.uk/news/midlands-news/more-500-police-communitysupport-10420554

HM Treasury 2015 Autumn Statement [accessed 02/01/15] Available at: https://www.gov.uk/government/publications/spending-review-and-autumn-statement-2015documents/spending-review-and-autumn-statement-2015 (Accessed: 29 December 2015)

Hobson, A. J., 2002 Student Teachers' Perceptions of School-based Mentoring in Initial Teacher Training (ITT) Mentoring \& Tutoring 10 (1), 5-20

Home Office 2013 'Police Workforce, England and Wales, 31 March 2013' https://www.gov.uk/government/statistics/police-workforce-england-and-wales-31-march2015

Jackson, A., 2009 Perceptions of Masters level PGCE: A pilot investigation The University of Cumbria and the ESCalate Initial Teacher Education Subject Centre of the Higher Education Academy [accessed 26th July 2010] Available at http://escalate.ac.uk/downloads/6461.pdf

Johnson, R.B. and Onwuegbuzie, A.J., 2004 Mixed methods research: A research paradigm whose time has come. Educational researcher 33 (7), 14-26

Johnston, L., 2005 From 'Community' to 'Neighbourhood' Policing: Police Community Support Officers and the 'Police Extended Family' in London Journal of Community \& Applied Social Psychology 15, 241-254

Kennedy, A., 2005 Models of Continuing Professional Development: a framework for analysis Journal of In-service Education. 31 (2), 235-250

Knowles, M.S., 1990 The Adult Learner: A Neglected Species. 4th edition, Houston: Gulf Publishing Company, Book Division

Korthagen, F. A. J. and Kessels, J. P. A., 1999 Linking Theory and Practice: Changing the Pedagogy of Teacher Education American Educational Research Association, 28 (4), 4-17

Lamont, E., Macleod, S. and Wilkin, A., 2011 Police Officers in Schools: A scoping study Slough: National Foundation for Educational Research 
Lewin, K., 1946 Action research and minority problems Journal of Social Issues, 2 (4), 34-46

Longstaff, A., Willer, J., Chapman, J. Czarnomski, S. and Graham, J., 2015 Neighbourhood policing: Past, present and future A review of the literature The Police Foundation May 2015

Lord, P., Lamont, E., Harland, J., Mitchell, H. and Straw, S., 2009 Evaluation of the GTC's Teacher Learning Academy (TLA): Impacts on teachers, pupils and schools Slough: National Foundation for Educational Research

Lyle, S. and Hendley, D., 2007 Can portfolios support critical reflection? Assessing the portfolios of Schools Liaison Police Officers Journal of In-Service Education 33 (2), 189207

McCarthy, N., 2015 "Heated exchanges at PCSO meeting with West Midlands Police Chief Constable as cuts announced" Birmingham Mail (28/06/15) [accessed 26/12/15] Available at http://www.birminghammail.co.uk/news/midlands-news/heated-exchanges-pcso-meetingwest-9745991

McNiff, J. and Whitehead, J., 2009 You and your action research project London: Routledge Newman, J.H., 1959 The idea of a university. New York: Doubleday

O’Brien, J. and Jones, K., 2014 Professional learning or professional development? Or continuing professional learning and development? Changing terminology, policy and practice Professional Development in Education, 40 (5), 683 - 687

O'Neill, M., 2015 The Case for the Acceptable 'Other': The Impact of Partnerships, PCSOs, and Neighbourhood Policing on Diversity Policing, 9 (1), 77-88

Piaget, J. (1972) The principles of genetic epistemology. New York: Viking

Perkins, D., 1999 The Many Faces of Constructivism Educational Leadership 57 (3), 6-11

Quinton, P. and Morris, J., 2008 'Neighbourhood policing: the impact of piloting and early national implementation' Home Office online report 01/08.

http://socialwelfare.bl.uk/subject-areas/services-activity/criminaljustice/homeoffice/141882rdsolr0108.pdf

Reeves, S., Zwarenstein, M., Goldman, J., Barr, H. Freeth, D., Hammick, M. and Koppel, I., 2008 Interprofessional Education: Effects on Professional Practice and Health Care

Outcomes The Cochrane Collaboration, The Cochrane Library: John Wiley \& Son. Issue 1

Rhodes, C.P., Stokes, M. and Hampton, G., 2004 A Practical Guide to Mentoring, Coaching and Peer-networking: Teacher Professional Development in Schools and Colleges London: Routledge

Robinson, M. and Cottrell, D., 2005 Health Professionals in Multi-Disciplinary and MultiAgency Teams: Changing Professional Practice Journal of Interprofessional Care, 19, (6), $547-560$ 
Schön, D. A., 1983 The Reflective Practitioner: How professionals think in action, Basic Books

Simkins, T., 2009 Integrating work-based learning into large-scale national leadership development programmes in the UK Educational Review 61 (4), 391-405

Stead, J., Lloyd, G., Baird, A., Brown, J., Riddell, S., Weedon, E. and Laugharne, J., 2011 All Wales School Liaison Core Programme (AWSLCP) Evaluation Report

Terpstra, J., 2010 Community Policing in the Netherlands and the use of other related police models: problem-oriented, disorder and reassuring policing Cahiers Politiestudies, Jaargang $10-3,(16), 215-232$

The Children Act 2004 London: Her Majestey's Stationery Office [accessed 05/02/16] Available at http://www.opsi.gov.uk/acts/acts2004/20040031.htm

Timperley, H.S. (2011) Realizing the Power of Professional Learning Maidenhead: Open University Press

University and College Union (UCU) 2015 The Prevent duty: A guide for branches and members

Vygotsky, L. S., 1962 Thought and language Cambridge [Mass]: M.I.T. Press

Walker, A. and Dimmock, C., 2006 Preparing leaders, preparing learners: The Hong Kong experience School Leadership and Management, 26 (2), 125-147

Wells, G., 2004 Dialogic Inquiry: Towards a theory and practice of education Cambridge University Press

White, D. and Heslop, B., 2012 Educating, Legitimising or Accessorising? Alternative conceptions of professional training in UK higher education: a comparative study of teacher, nurse and police officer educators Police Practice and Research, 13 (4), 342-356 